\title{
MONITORAMENTO DE IMPACTOS AMBIENTAIS NA TRILHA DO SALTO VENTOSO, FARROUPILHA - RS
}

\author{
MONITORING ENVIRONMENTAL IMPACTS ON THE SALTO VENTOSO TRAIL, FARROUPILHA - RS \\ MONITORIZACIÓN DE IMPACTOS AMBIENTALES EN EL SENDERO DE SALTO VENTOSO, \\ FARROUPILHA - RS
}

Paulo Roberto Teixeira

Universidade Estadual de Roraima

prt.teixeira@gmail.com

Mestre em Turismo; Especialista em Geografia e Meio Ambiente; Turismólogo

Rita Lourdes Michelin

Universidade Estadual de Roraima

rita.michelin@gmail.com

Mestre em Turismo; Turismóloga

Data de Submissão: 07/02/2013

Data de Aprovação: 29/042013

\section{RESUMO}

O Salto Ventoso está localizado no município de Farroupilha - RS e se caracteriza por ser um atrativo turístico de grande importância para a região. O local é uma área particular, possui uma cascata de 60 metros de altura e sua paisagem cênica atrai diversos visitantes nos finais de semana. No ano de 2011 sua trilha foi mapeada, utilizando ferramentas de geoprocessamento, o que gerou um mapa dos impactos. No ano de 2012 foram aplicados os mesmos instrumentos e parâmetros (largura da trilha, trilhas secundárias, danos à infraestrutura e aos recursos naturais) para monitorar a evolução dos impactos, utilizando-se da mesma metodologia. Os resultados demonstraram que o local apresenta, em alguns pontos, uma sensível melhora, porém ainda há uma série de impactos, resultantes da visitação e da falta de planejamento e manutenção.

PALAVRAS-CHAVE: Impacto Ambiental. Turismo. Monitoramento de Impactos. Salto Ventoso.

ABSTRACT

Salto Ventoso is located in the town of Farroupilha, and is characterized as a tourist attraction of great importance for the region. The site covers a particular area, comprising a waterfall 60 meters in height and the scenic natural setting around it, attracting visitors on weekends. In 2011, a trail was mapped using GIS tools, which generated an impact map. In 2012, the same tools and parameters were applied (track width, secondary trails, damage to infrastructure and natural resources) to monitor the evolution of the impacts, using the same methodology. The results showed that in some places, the site has shown significant improvement, but there are still a number of impacts resulting from visitation and a lack of planning and maintenance.

KEY-WORDS: Environmental Impact. Tourism. Monitoring Impacts. Salto Ventoso. 
El Salto Ventoso está ubicado en el municipio de Farroupilha - RS y se caracteriza por ser una atracción turística de gran importancia para la región. El sitio es un área particular, posee una cascada de 60 metros de altura y su paisaje atrae a diversos visitantes durante los fines de semana. En el año 2011 su sendero fue mapeado utilizando herramientas de geoprocesamiento, lo que generó un mapa de los impactos. En el año 2012 se aplicaron los mismos instrumentos y parámetros (ancho del Sendero, senderos secundarios, daños a la infraestructura y a los recursos naturales) para monitorear la evolución de los impactos, utilizando la misma metodología. Los resultados demostraron que el sitio presenta, en algunos puntos, una sensible mejoría, aunque todavía hay una serie de impactos resultantes de la visitación y de la falta de planeamiento y manutención.

PALABRAS CLAVE: Impacto Ambiental. Turismo. Monitorización de Impactos. Salto Ventoso.

\title{
INTRODUÇÃO
}

A valorização da natureza e a motivação em sair dos centros urbanos têm contribuído para que o turismo realizado em ambientes naturais torne-se um fenômeno cada vez mais crescente em todo o mundo. As distintas formas de ação do ser humano sobre o meio ambiente ao longo da sua evolução são hoje reconhecidas como tema essencial para a pesquisa científica, sob a responsabilidade de se buscar soluções ou alternativas de uso humano compatíveis com a conservação dos recursos naturais e culturais (RUDZEWICZ et al. 2008). A demanda turística pelos recursos naturais é crescente diante da expansão dos segmentos de turismo ligados à natureza: ecoturismo, turismo de aventura, turismo rural, agroturismo, turismo científico, turismo de natureza, entre outros.

A ação antrópica vem sendo responsável pela destruição dos ecossistemas e com isso tem colocado em risco a sobrevivência das diferentes formas de vida na Terra. Sendo assim, de acordo com Rudzewicz et al. (2008), o estudo da relação entre o turismo e o meio ambiente pode auxiliar na preservação de ecossistemas, uma vez que esses são de grande importância para o turismo que utiliza a natureza como atrativo.

A relação existente entre os recursos naturais e o turismo é, portanto, invariável, resultando na busca de um ponto de equilíbrio entre seu uso e proteção pela própria perpetuação da atividade turística (RUSCHMANN, 2003). A demanda turística pelos recursos naturais é crescente diante da expansão das formas de turismo ligadas à natureza e toda visitação nesses locais causa algum tipo de impacto. $\mathrm{O}$ turismo se utiliza de ambientes naturais como forma de atrativo, portanto o estudo dos impactos que a presença do homem causa nesses ambientes é de extrema necessidade. Para impacto ambiental, adotou-se a definição do CONAMA 001/86, que considera como:

\begin{abstract}
Qualquer alteração das propriedades físicas, químicas e biológicas do meio ambiente, causada por qualquer forma de matéria ou energia resultante das atividades humanas que, direta ou indiretamente afetam: a saúde, a segurança e o bem-estar da população; as atividades sociais e econômicas; a biota; as condições estéticas e sanitárias do meio ambiente; a qualidade dos recursos ambientais. (BRASIL, 2008, p. 41).
\end{abstract}

Para resolver um problema ambiental, "deve-se isolar suas causas, elaborar estratégias para eliminá-las ou minimizá-las, estabelecer metas e acompanhar a implementação, até que tenham sido atingidas as metas ou o problema tenha sido resolvido" (MITRAUD, 2003, p. 315). Neste contexto, a escolha do local conhecido como Salto Ventoso, no interior da cidade gaúcha de Farroupilha é pertinente, uma vez que sua condição como atrativo turístico natural, aliado à falta de planejamento para receber visitantes, transforma a área em um gerador de impactos ambientais. Esses poderiam ser reduzidos, se técnicas de manejo e controle fossem efetivamente implementadas.

Para Lechner (2006), a sustentabilidade das trilhas é obtida mediante o uso de técnicas de manejo, integrando o planejamento, a construção, a manutenção, o monitoramento e a avaliação. Esse sistema de planejamento aborda a análise do perfil do público, suas atividades, além do uso de técnicas de manejo específicas para que o impacto seja mitigado ao máximo. 
No ano de 2011 foi realizado o levantamento dos impactos na trilha do Salto Ventoso (TEIXEIRA; AHLERT, 2011), onde foram analisados indicadores de impactos causados pela visitação no local. O presente trabalho tem o objetivo de monitorar os mesmos parâmetros, com o objetivo de manter um registro histórico das mudanças ocorridas naquela área. Os procedimentos metodológicos foram os mesmos do estudo anterior, assim como os parâmetros de avaliação.

\section{CARACTERIZAÇÃO DO LOCAL DA PESQUISA}

A área de estudo é a trilha que está inserida do atrativo turístico conhecido como Salto Ventoso, localizado no município de Farroupilha - RS, sob as coordenadas $29017^{\prime} 6$ ' 'S e $51^{\circ} 24^{\prime} 43^{\prime}$ 'W (Figura 1). O acesso ao local é feito somente por estrada de chão e está a $15 \mathrm{~km}$ de Farroupilha. O principal atrativo é uma cascata com aproximadamente 60 metros e uma área natural na qual os visitantes podem realizar caminhadas e tomar banho no rio.

O maior fluxo de visitantes concentra-se nos finais de semana e feriados, principalmente no verão. As atividades realizadas no local são caminhadas, banhos, acampamentos, prática de escalada por esportistas e uso, por empresas de turismo de aventura, para comercialização do rapel, que se caracteriza por uma "técnica vertical de descida em corda" (BRASIL, 2006).

Figura 1: Mapa de localização do Salto Ventoso - Farroupilha, RS

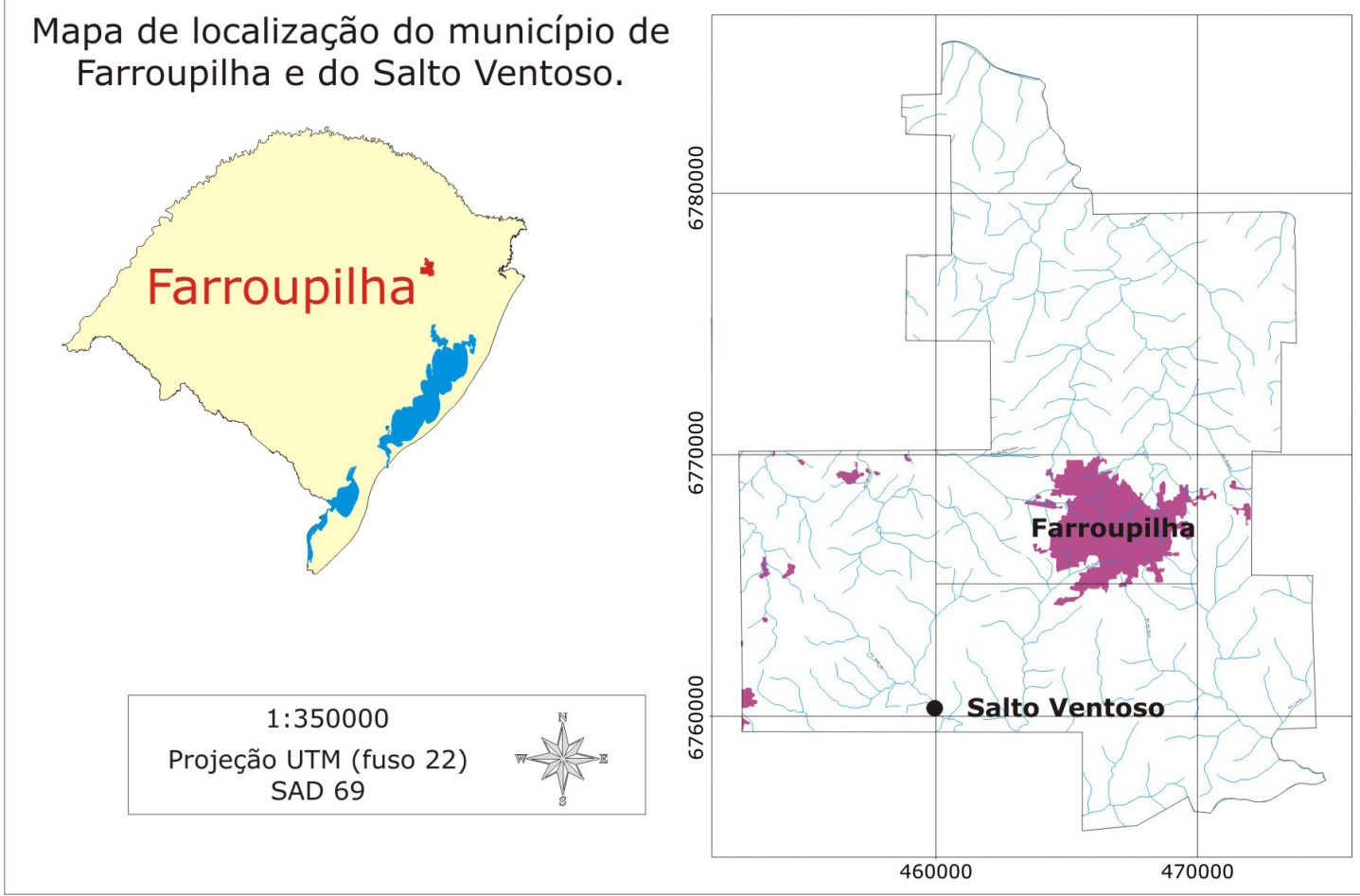

Fonte: Teixeira e Ahlert, 2011.

A área é particular e os proprietários moram no local, e esses mantêm um pequeno comércio, principalmente de bebidas e lanches rápidos, para suprir as necessidades dos frequentadores. A estrutura disponibiliza banheiros para o público, estacionamento pago, churrasqueiras e área de camping. Cabe ressaltar que o pagamento é feito somente para estacionar o carro, se o frequentador deixar o veículo no lado de fora da propriedade, pode acessá-la sem custo.

\section{MÉTODO}

O método envolveu, em uma primeira fase, o mapeamento da trilha por meio de ferramentas de geotecnologias, como o GPS para georreferenciar os locais dos impactos e teodolito, para identificar 
os locais da trilha mais suscetíveis à degradação devido à sua inclinação. Os dados foram analisados utilizando ferramentas de Sistema de Informação Georreferenciada (SIG) e serviram como base para elaboração dos mapas dos impactos no local. Esse levantamento foi realizado no ano de 2011 e proporcionou identificar e conhecer o cenário no qual se estava trabalhando.

No mesmo período de 2011 foi aplicada uma ficha de avaliação de impactos, baseada em Lobo e Simões (2009), com os seguintes critérios de análise: largura da trilha; danos aos recursos naturais (quebra de galhos, inscrições em árvores, plantas pisoteadas fora da trilha, vandalismo e queimadas); danos à infraestrutura (pichação, remoção de estruturas, vandalismo), que foram observados nos 13 pontos de amostragem. Já os parâmetros: número de trilhas não oficiais; problemas de drenagem (empoçamentos, falta de sistema de drenagem; falta de manutenção nas canaletas/sistema de drenagem e erosão) e presença de lixo, foram observados ao longo de toda trilha.

A trilha, que possui 720 metros, foi mapeada e dividida em trechos, estabelecendo distâncias fixas entre os pontos de amostragem para as observações e as medições. Foram estabelecidos 13 pontos de amostragem, com intervalo de 60 metros. Para a presente pesquisa, no ano de 2012, o instrumento foi novamente aplicado, nos referentes pontos de amostragem, seguindo os mesmos critérios utilizados em 2011 por Teixeira e Ahlert (2011).

\section{RESULTADOS E DISCUSSÃO}

A trilha estudada é classificada como atalho, pois inicia em um ponto e finaliza em outro (ANDRADE, 2003). Por meio do estudo anteriormente realizado, verificou-se que a trilha está dividida em três ambientes. O primeiro, do ponto 1 ao 7 , apresenta uma largura que varia de $3 \mathrm{~m}$ a $5,6 \mathrm{~m}$, pois permitia o acesso por veículos. $\mathrm{O}$ segundo, entre os pontos 7 e 11 , é mais estreito e somente pode ser feito a pé, uma vez que a trilha passa por trás da queda d’água. Nesse trecho ocorre a maior parte das visitas, por apresentar uma maior beleza cênica e a trilha não oferecer grandes dificuldades, sendo o ponto em que a maioria dos visitantes retorna. O último trecho, entre os pontos 11 e 13, apresenta a menor quantidade de impactos e de visitantes devido à alteração de características, como vegetação mais densa, que dificulta a caminhada; e paisagem pouco atrativa, pois não se avista mais a cascata (Figura 2). 
Figura 2: Mapa da trilha do Salto Ventoso com os pontos de monitoramento

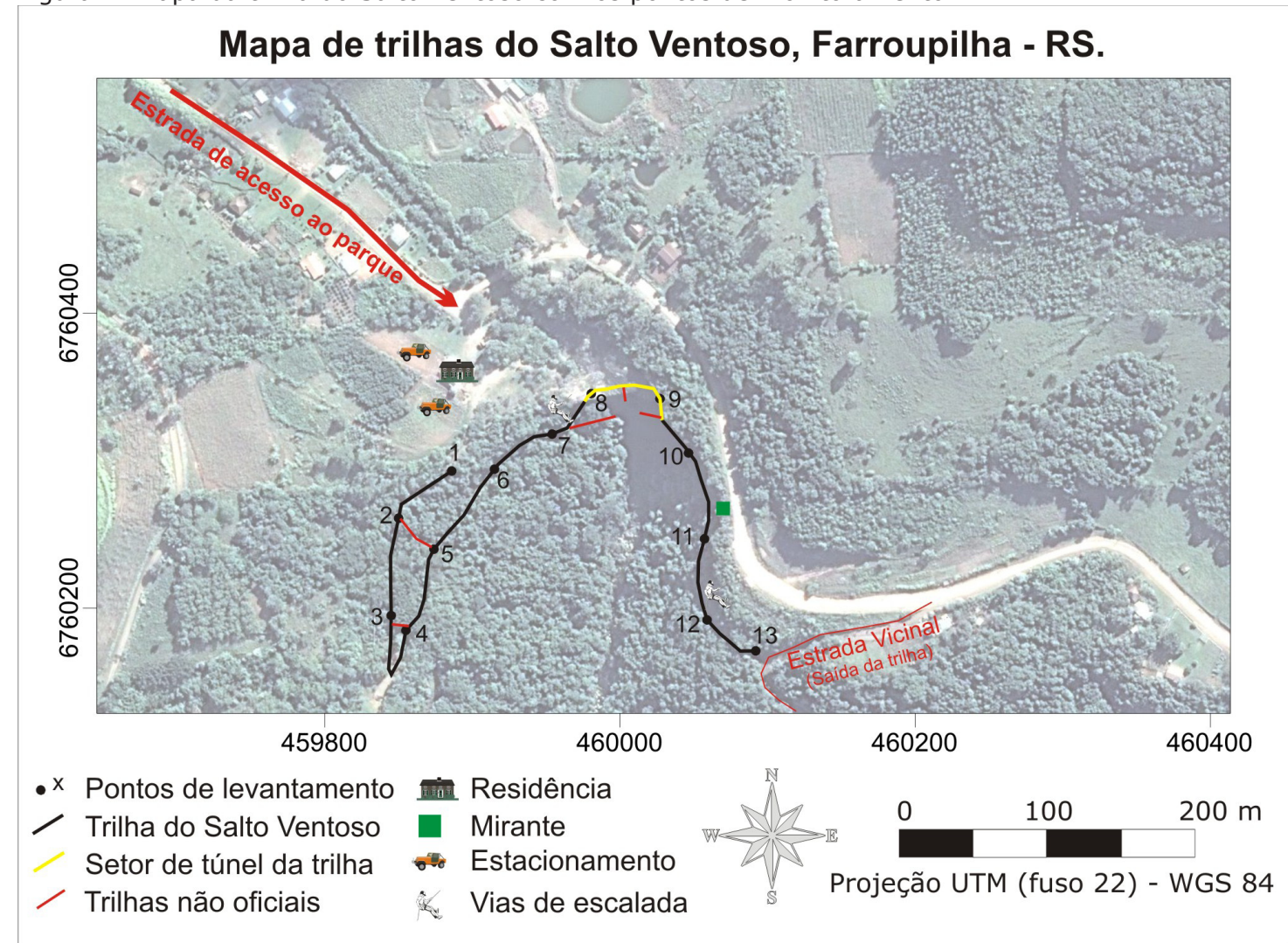

Fonte: Teixeira e Ahlert, 2011.

Para avaliar e monitorar a largura da trilha, foi utilizado o padrão estabelecido por Mitraud (2003, p. 36), que estabelece que a largura máxima deve ser de " 1,5 a $2 \mathrm{~m}$ como trilha desenvolvida e até 50 cm de cada lado como o impacto de visitação" e a vegetação e o solo podem estar danificados, mas não eliminados ou expostos. Fixou-se, portanto, o máximo de 2 metros. Os resultados demonstraram que, em 2011 , 38,5\% dos pontos de amostragem apresentam a largura dentro dos padrões.

Em 2012 esse percentual aumentou para 46,1\% (Figura 3). A largura média em 2011 era de 2,80m, já em 2012 os resultados apresentaram 2,40m, uma redução de 16,6\%. A maior redução na largura da trilha ocorreu entre os pontos 2 a 6 , trecho que passou a ser pouco utilizado pelos visitantes após a abertura da trilha secundária no ponto 2, ligando-o ao ponto 5 , que se tornou o principal caminho (Figura 2). 
Figura 3: Largura da trilha do Salto Ventoso no ano de 2011 e 2012 em cada ponto de monitoramento, os valores abaixo de 2 metros encontram-se dentro do padrão estabelecido

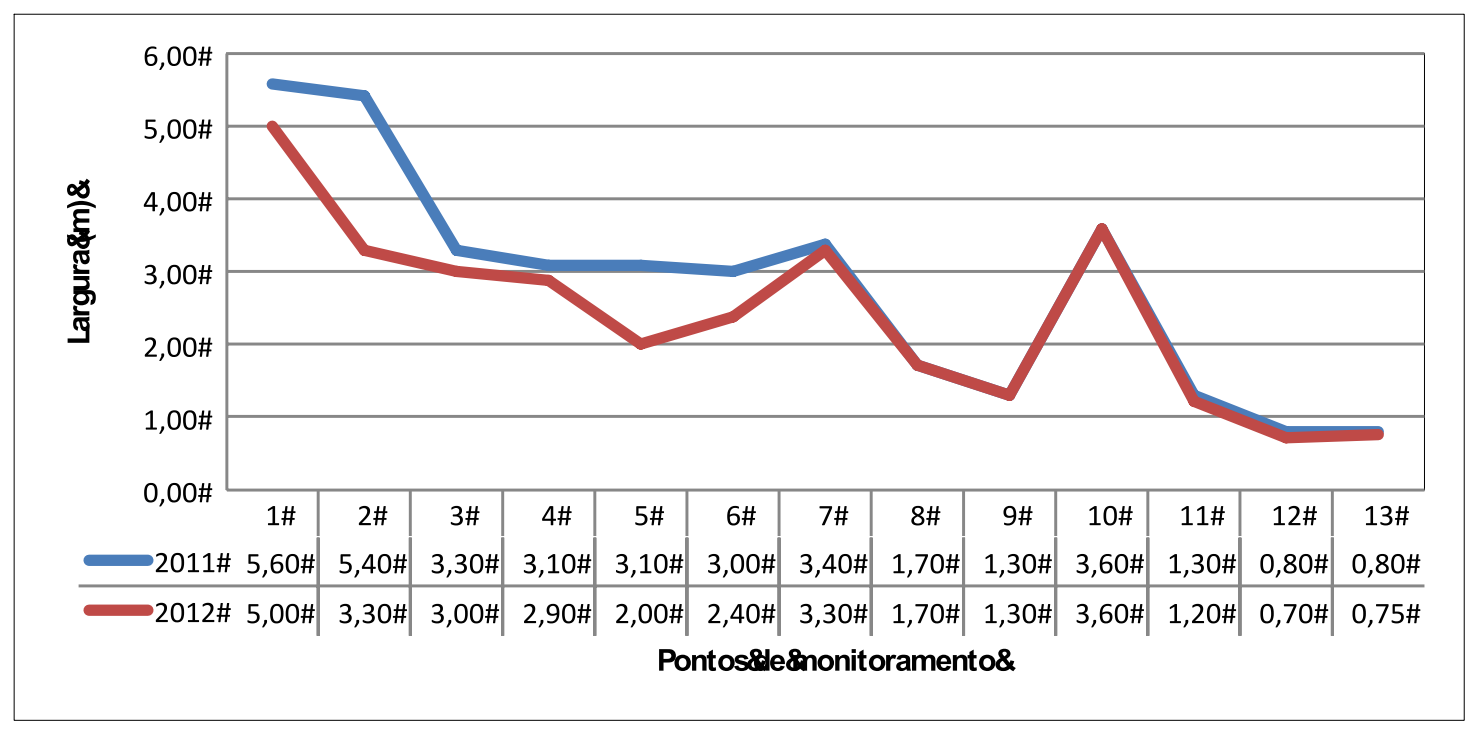

A largura excessiva da trilha entre os pontos 1 a 3 deve-se ao fato de que essa era uma antiga estrada de carros e onde as pessoas estacionavam seus veículos, no entanto, após a abertura da trilha secundária e com a delimitação de espaços de estacionamento por parte dos proprietários da área, os visitantes não mais adentram a trilha em veículos motorizados. Fator esse que tem contribuído para a redução na largura nesse trecho da trilha.

Atualmente, todo acesso à trilha é realizado a pé, o que auxilia na sua recuperação. Para Andrade (2003), as trilhas deveriam ter apenas a largura que permitisse a passagem de uma pessoa de cada vez, isso reduziria o pisoteio e os impactos da visitação. Portanto ações de controle e manejo são muito importantes. Estratégias de manejo, como delimitar as bordas da trilha, auxiliariam na diminuição desse alargamento. Para a demarcação das laterais da trilha, podem ser utilizados troncos de madeira ou rochas, além disso esse cercamento se ergue sobre a borda da trilha, diminuindo a ação erosiva da água (LECHNER, 2006). Sugere-se, ainda, a instalação de corrimões, principalmente no trecho 10 e 11, onde a inclinação varia entre $22 \%$ a 30\% (TEIXEIRA; AHLERT, 2011), e no qual não houve redução na largura da trilha.

Os indicadores de impacto relacionados aos recursos naturais são os diretamente relacionados à ação antrópica, como quebra de galhos, inscrições em árvores, plantas pisoteadas fora da trilha, vandalismo e queimadas. O padrão máximo estabelecido para esse tipo de impacto foi de $25 \%$. Os resultados demonstraram que entre o ano de 2011 e 2012 houve um aumento de 53,85\% para $61,54 \%$ dos impactos relacionados a esses parâmetros (Figura 4). No local da pesquisa não há fiscalização, normas de conduta ou trabalhos de sensibilização do visitante assim que chega ao local, o que favorece o aumento dos impactos. Para Andrade (2008), as trilhas necessitam de uma manutenção constante para minimizar os impactos que venham a ser provocados pela visitação. 
Figura 4: Comparativo entre 2011 e 2012 do monitoramento de impactos, demonstrando a relação entre o padrão máximo de impacto estabelecido e os valores encontrados no local

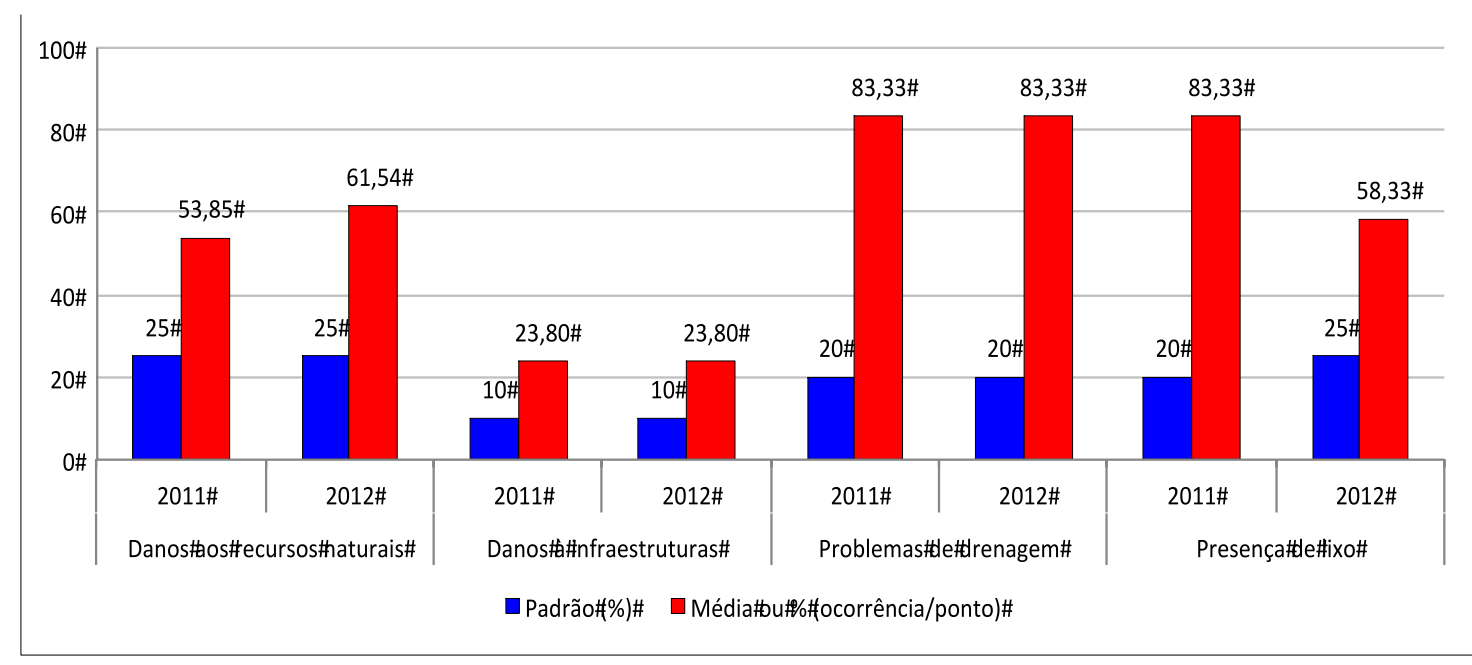

Dentre as estratégias de manejo de trilhas que poderiam ser implantadas para a redução dos danos aos recursos naturais, seria a informação aos visitantes sobre o que é permitido realizar dentro daquela área, por meio de placas interpretativas instaladas na entrada do parque, onde fica a casa dos proprietários, evitando assim o vandalismo e um trabalho mais próximo com o público, a fim de informar os visitantes das normas de conduta do local e as consequências que posturas inadequadas podem trazer ao meio ambiente e à qualidade da visita. Outra estratégia seria de elaborar um sistema de fiscalização do local, principalmente nos finais de semana, período com o maior número de visitantes no local, nesse caso o proprietário deveria investir em mão de obra, pois possuiu um negócio familiar e não consegue dar conta de controlar as ações dos frequentadores.

De forma geral, o Salto Ventoso apresenta deficiência na infraestrutura, tanto na área de lazer quanto na trilha para cascata. Os resultados demonstraram que em muitos pontos da trilha a falta de infraestrutura é um agravante para a natureza e para os visitantes. O padrão estabelecido para danos à infraestrutura foi de $20 \%$. Os resultados demonstraram que não houve alteração neste valor nos dois anos de medições, que é de $23,8 \%$ dos pontos observados (Figura 4).

O desrespeito a pouca infraestrutura existente foi evidenciado por meio do vandalismo nas placas de identificação de pontos da trilha, remoção de estruturas utilizadas para limitar o acesso de carros e pessoas, assim como a pichação nas rochas, principalmente debaixo da cascata. A infraestrutura na trilha se caracteriza por: uma escada no trecho 7-8; uma contenção para automóveis no trecho 3-4; lixeiras espalhadas entre os trechos 1 a 8; algumas placas de avisos próximas à cascata e no seu topo e uma ponte de madeira improvisada no trecho 8-9, que foi colocada para permitir a passagem devido à erosão que está contribuindo para o desmoronamento da trilha, causada pela abertura de uma trilha secundária.

As trilhas secundárias devem ser consideradas ao se analisar os impactos ambientais, pois as mesmas se tratam de caminhos abertos sem técnicas de manejo adequado, que acabam causando erosão e destruição da vegetação. De acordo com Lobo e Simões (2009), os motivos para a abertura dessas trilhas não oficiais podem ser o encurtamento do trajeto, acesso à água ou até mesmo o desvio de um obstáculo.

No Salto Ventoso foram encontradas cinco trilhas não oficiais no ano de 2011 , número que se reduziu para dois em 2012. A trilha secundária localizada entre os trechos 3 e 4, que tinha o objetivo de encurtamento de percurso, atualmente está totalmente fechada, uma vez que está localizada no trecho em desuso devido à abertura do atalho no ponto 2 (Figura 2). A trilha, que liga o ponto 2 ao 5, aberta pelo proprietário da área com o objetivo de encurtamento de percurso, mesmo não obedecendo a uma metodologia de construção de trilhas, passou a ser a principal. Esse ponto se tornou um local muito impactado, devido à falta de cobertura vegetal, associado à inclinação que varia de $18 \%$ a $29 \%$ (TEIXEIRA; AHLERT, 2011). A trilha que havia no trecho 7-8 está totalmente recuperada e não apresenta sinais de uso. A que está no ponto 9-10, que tem o objetivo de acesso à água, apresenta sinais claros de pouco uso e de recuperação. 


\section{Turismō}

No entanto a trilha secundária no trecho 8-9 deve ser tratada com especial atenção, pois está localizada no trecho que passa atrás da cascata e que vem ocasionando um desmoronamento na trilha principal (Figura 5). O impacto causado por essa trilha secundária foi observado no primeiro levantamento (TEIXEIRA; AHLERT, 2011), descrevendo que a solução temporária foi a colocação de tábuas para ultrapassar o obstáculo. Atualmente o impacto ainda é presente e a solução continua a mesma, sendo que nenhuma outra providência foi tomada para reverter o desmoronamento, que continua afetando a trilha principal.

Figura 5: Erosão causada pela trilha secundária localizada no trecho 8-9, a alternativa para a passagem das pessoas foi por meio da improvisação de uma ponte de tábuas

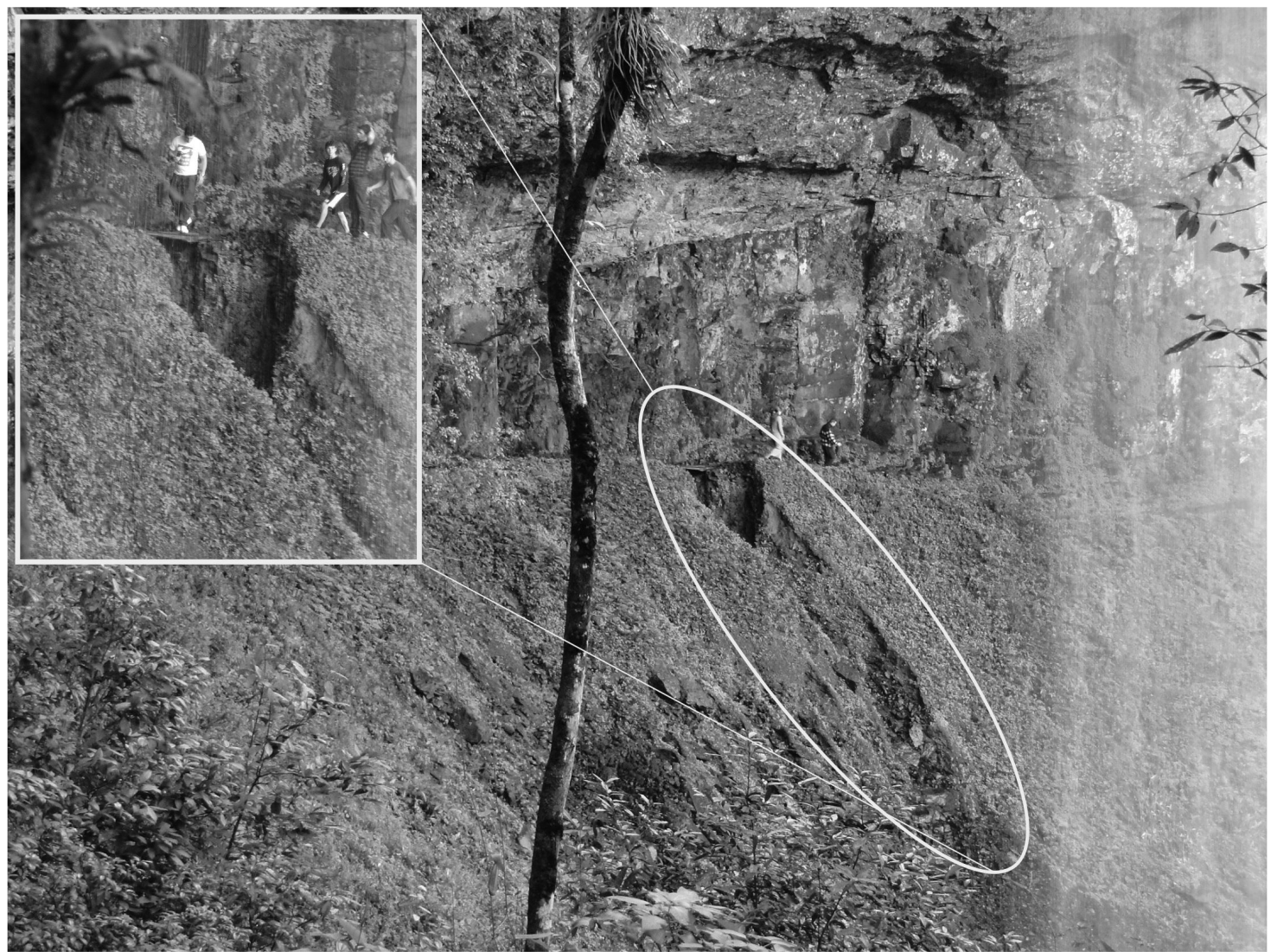

Foto: Rita Michelin.

Por estar localizado atrás da cascata, o local fica constantemente úmido ou molhado, comprometendo a durabilidade das tábuas e colocando em risco os visitantes. Esse impacto correu devido ao acesso à água por meio do uso de uma trilha não oficial. Existe um trajeto para esse fim localizado próximo ao ponto 10 , no entanto, para encurtar caminho, algumas pessoas passaram a utilizar esse acesso, que, por meio de medições, possui inclinação acima de $85 \%$ e uma cobertura vegetal frágil.

A erosão do solo expõe as raízes das plantas, dificultando sua sustentação, além de causar acidentes às pessoas que estão visitando o local. Esse é um problema grave e pode ser, em alguns casos, irreversível, e a recuperação dessas áreas é extremamente onerosa e não garante a completa reabilitação do local (LOBO; SIMÕES, 2009). Quando se trata do solo, Andrade (2003) afirma que existem dois fatores de alteração decorrente do uso desse: compactação e erosão.

O efeito do pisoteio produz um impacto mecânico direto, que resulta na exposição das raízes das árvores, causando riscos de doenças e quedas, e na diminuição da capacidade de retenção de ar e absorção de água, alterando a capacidade do solo de sustentar a vida vegetal e animal associada. (ANDRADE, 2003, p. 250).

Com relação ao trecho 8-9, sugere-se a construção de uma pequena trilha suspensa ou ponte no local, uma vez que a improvisação realizada pelo proprietário coloca os visitantes em uma situação 
de risco. Para Hesselbarth (2007, p. 103), "as pontes podem variar desde um simples pontilhão com um corrimão a estruturas com múltiplas seções suspensas, enfeixadas e treliçadas".

Com relação à drenagem, foram verificados empoçamentos, o que dificulta a caminhada dos visitantes e a falta de manutenção dos sistemas de drenagem existentes. O padrão máximo estabelecido foi de $20 \%$, no entanto, em $83,33 \%$ dos pontos há falhas no sistema de drenagem ou inexistem (Figura 4). Esses dados são de 2011 e 2012, demonstrando que no local não houve qualquer melhoria nesse sentido. Lechner (2006) destaca que o sistema de drenagem constitui na técnica mais efetiva para manejo de água, podendo ser construídas por meio de reversão de declividade e drenos naturais ou valas de drenagem.

Essa falta de manutenção em alguns trechos pode causar acidentes, pois em muitos pontos a trilha é úmida por causa da proximidade da cascata, deixando o chão escorregadio e facilitando quedas. Lobo e Simões (2009) afirmam que é comum verificar a presença de problemas de drenagem em trilhas mal planejadas, em que o problema existe independentemente do uso ou da sua intensidade e que esse parâmetro pode ser seriamente agravado com o uso público. Na trilha do Salto Ventoso existem diversos pontos que necessitam de manutenção ou implantação de sistemas para escoamento da água e como quase toda a trilha é uma ascendente e descendente, pode-se construir valetas de drenagem ou bolsões de escoamento, podendo, assim, reduzir consideravelmente os problemas de drenagem.

A presença de lixo é uma constante em vários pontos da trilha, no entanto, entre 2011 e 2012, verificou-se uma diminuição na quantidade de resíduos encontrados no leito da trilha. No primeiro ano, verificaram-se, através da contagem direta, 142 ocorrências, já no segundo ano esse número diminuiu para 75 . Essa redução de $47 \%$ na quantidade de lixo é significativa na medida em que a presença de lixo causa uma série de problemas, desde os ambientais, como o acúmulo de latas e plásticos, entre outros; além dos sociais, como impacto visual e a consequente insatisfação do visitante por estar em um local sujo. A redução ocorreu por dois motivos. O primeiro é a intensificação da limpeza por parte do proprietário e a segunda é o fato do trecho 2 a 5 (Figura 2) não serem mais utilizados, isso faz com que a contagem de lixo entre esses pontos ser quase zero.

De forma geral, percebe-se que os proprietários da área ainda não se conscientizaram da importância das técnicas de manejo para a manutenção da trilha e da importância da preservação dos recursos naturais para o desenvolvimento de atividades turísticas no local. No entanto problemas mais visíveis, como a presença de lixo, já têm chamado a atenção dos mesmos que tem intensificado a limpeza da trilha.

\section{CONSIDERAÇÕES FINAIS}

O Salto Ventoso caracteriza-se como um importante atrativo turístico do município de Farroupilha, no entanto ainda necessita de muitas ações para ter uma estrutura em condições adequadas para receber visitações. Por se tratar de um espaço natural, os impactos a esses recursos são os mais perceptíveis. Lembrando o apresentado por Ruschmann (2003) que a relação entre o turismo e os recursos naturais é invariável, pois aquele necessita desses para se desenvolver, por esse motivo, ressalta-se a importância do planejamento para o desenvolvimento responsável das atividades turísticas no meio natural, como o Salto Ventoso.

Considerando a importância de tal atrativo e dos recursos naturais para o turismo, o monitoramento dos impactos ambientais no local é fundamental para elaboração de estratégias de manejo, visando ao melhor aproveitamento do local com o mínimo impacto.

Comparando os dados referentes ao ano de 2011 (TEIXEIRA; AHLERT) com os atuais, de 2012, percebe-se como fator positivo a diminuição da largura da trilha em diversos pontos, sendo os locais de maior redução aqueles em que a trilha já não vem mais sendo utilizada, devido a um desvio, que se tornou o caminho principal. No entanto vale ressaltar que esse fator positivo resultou de um fator negativo de grande impacto, que foi a abertura de uma nova trilha. Outra questão a se destacar nesse indicador é que ainda existem pontos da trilha em que não houve redução na sua largura, sendo necessária a aplicação de técnicas de manejo adequadas para que se obtenha tal resultado, como, por exemplo, a instalação de corrimões entre os pontos 10 e 11 que possuem elevada inclinação. 
Como fator positivo a se destacar, foi a constatação da diminuição de lixo ao longo da trilha, de 83,33\% em 2011 para 58,33\% em 2012. Percebendo-se, nesse indicador, um maior cuidado por parte dos proprietários da área em manter a mesma visualmente limpa. Além disso, é importante considerar que alguns frequentadores do local para a prática da escalada tem o costume de recolher o lixo que encontram na trilha, assim, também contribuindo para essa redução.

Quanto aos danos aos recursos naturais, houve um aumento dos impactos causados diretamente pela ação antrópica, demonstrando a necessidade de estratégias para informar os visitantes, objetivando a sua sensibilização quanto aos recursos naturais e até mesmo um controle mais direto nas visitações por parte dos proprietários do local.

Conforme apresentado, a erosão causada na trilha principal entre os pontos 8 e 9, por causa da trilha secundária, necessita de técnicas de manejo com a maior brevidade, pois a solução temporária encontrada pelo proprietário da área não contribui para a redução de tal impacto a longo prazo, além de comprometer a segurança dos visitantes. A manutenção deve ser feita nesse local, pois não há um caminho alternativo, como técnica de manejo adequada, sugerindo-se o uso de uma trilha suspensa. Com relação às trilhas secundárias que ainda existem, o plantio de plantas ou arbustos e a colocação de galhos já dificultaria e sua utilização, dessa forma, contribuindo para que a natureza possa se recuperar nesses espaços.

Em suma, o monitoramento dos impactos ambientais no Salto Ventoso é de extrema importância para acompanhar a melhoria ou a degradação do local, pois por meio de um registro histórico é possível realizar um planejamento adequado e propor as ações adequadas de manejo ao local. Atualmente, as atividades turísticas que ocorrem no local ainda são incipientes e não apresentam nenhum planejamento prévio. Considerando a importância tanto turística quanto natural da área, tem-se o monitoramento como a base para o desenvolvimento de técnicas de manejo adequadas para a trilha e, dessa forma, contribuir para o futuro planejamento das atividades a serem realizadas no atrativo.

Artigo apresentado no VII Seminário de Pesquisa em Turismo do Mercosul. Universidade de Caxias do Sul - RS, novembro de 2012.

\section{REFERÊNCIAS}

ANDRADE, W. J. Implantação e manejo de trilhas. In: MITRAUD, Sylvia (Org.). Manual de Ecoturismo de Base Comunitária: ferramentas para um planejamento responsável. Brasília: WWF Brasil, 2003.

ANDRADE, W. J.; ROCHA, R. F. Manual de trilhas: um manual para gestores. Série Registros, São Paulo, n. 35, maio 2008.

BRASIL. Ministério do Turismo. Secretaria Nacional de Políticas de Turismo. Turismo de aventura: orientações básicas. Ministério do Turismo - Coordenação Geral de Segmentação. Brasília: Ministério do Turismo, 2006.

BRASIL. Ministério do Meio Ambiente. Legislação Ambiental Básica: Ministério do Meio Ambiente. Consultoria Jurídica. Brasília: Ministério do Meio Ambiente, UNESCO, 2008.

HESSELBARTH, Woody. Manual de Construção e Manutenção de Trilhas. São Paulo: Secretaria de Meio Ambiente, 2009.

LECHNER, Larry. Planejamento, implantação e manejo de trilhas em Unidades de Conservação. Curitiba: Fundação O Boticário de Proteção à Natureza, 2006.

LOBO, A. C.; SIMÕES, L. L. Manual de Monitoramento e Gestão dos Impactos da Visitação em Unidades de Conservação. São Paulo: Secretaria de Meio Ambiente de São Paulo, 2009.

MITRAUD, S. Monitoramento e controle de impactos de visitação. In: MITRAUD, Sylvia (Org.). Manual de Ecoturismo de Base Comunitária: ferramentas para um planejamento responsável. Brasília: WWF Brasil. 2003.

RUDZEWICZ, Laura; TEIXEIRA, Paulo R.; LANZER, Rosane; SHAFER, Alois. Turismo e Recursos Naturais: a visão das comunidades dos municípios do litoral médio e sul do Rio Grande do Sul. In: SeminTUR. Turismo: Inovações da Pesquisa na América Latina. Universidade de Caxias do Sul - UCS, Caxias do Sul. 2008. 
RUSCHMANN, D. Turismo e planejamento sustentável: a proteção do meio ambiente. 10. ed. Campinas: Papirus, 2003.

TEIXEIRA, Paulo Roberto; AHLERT, Siclério. O uso de geotecnologias na análise dos impactos ambientais no Salto Ventoso (Farroupilha/RS). Revista Brasileira de Pesquisa em Turismo. v.5, n.3, p.309-324, dez. 2011. 